Research Paper

\title{
Visualization and bibliometric analysis of cAMP signaling system research trends and hotspots in cancer
}

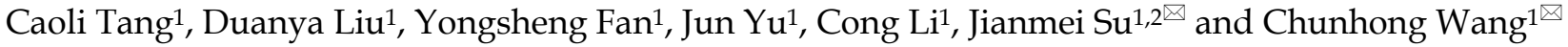 \\ 1. Department of Preventive Medicine, School of Public Health, Wuhan University, Donghu Road 115, Wuhan 430071, Hubei, China. \\ 2. Key Laboratory of Regional Development and Environmental Response, Faculty of Resources and Environmental Science, Hubei University, Friendship \\ Avenue 368, Wuhan 430062, Hubei, China. \\ $\square$ Corresponding author: Department of Preventive Medicine, School of Public Health, Wuhan University, Donghu Road 115, Wuhan 430071, Hubei, China. \\ E-mail address: sujianmei@whu.edu.cn (J. Su); wchunhong027@whu.edu.cn (C. Wang). \\ (c) The author(s). This is an open access article distributed under the terms of the Creative Commons Attribution License (https://creativecommons.org/licenses/by/4.0/). \\ See http://ivyspring.com/terms for full terms and conditions.
}

Received: 2020.04.18; Accepted: 2020.10.02; Published: 2021.01.01

\begin{abstract}
Cyclic adenosine monophosphate (cAMP) is an essential second messenger that widely distributed among prokaryotic and eukaryotic organisms. cAMP can regulate various biological processes, including cell proliferation, differentiation, apoptosis and immune functions. Any dysregulation or alteration of cAMP signaling may cause cell metabolic disorder, immune dysfunction and lead to disease or cancer. This study aimed to conduct a scientometric analysis of cAMP signaling system in cancer field, and explored the research trend, hotspots and frontiers from the past decade. Relevant literatures published from 2009 to 2019 were collected in the Web of Science Core Collection database. EndNote X9 was used to remove duplicate articles, and irrelevant articles were manually filtered. Bibliometric analyses were completed by CiteSpace V. A total of 4306 articles were included in this study. The number of related literatures published each year is gradually increasing. Most of them belong to "Biochemistry \& Molecular Biology", "Oncology", "Cell Biology", "Pharmacology \& Pharmacy" and "Endocrinology \& Metabolism" areas. In the past decade, USA, China, and Japan contributed the most to the research of CAMP signaling system in cancer. The frontiers and hotspots of CAMP signaling pathway system related to cancer fields mainly focused on cancer cell apoptosis, metastasis, and multiple tumors occurrence in patients with Carney complex. Intervention of the CAMP metabolic pathway may be a potential and promising therapeutic strategy for controlling clinical cancer and tumor diseases.
\end{abstract}

Key words: cAMP; Cancer; CiteSpace; Bibliometrics; Hotspots

\section{Introduction}

Cyclic adenosine monophosphate (cAMP) is an important cellular second messenger that firstly discovered in 1956 [1] and widely distributed among prokaryotic and eukaryotic organisms. cAMP mediates a multitude of cellular processes and biological functions [2], including gene regulation, cell proliferation and differentiation, apoptosis, energy metabolism, memory formation, neurotransmission, intestinal secretion, retinal phototransduction and immune functions [3-9]. cAMP is formed from ATP by adenylyl cyclases (ACs) and hydrolyzed by phosphodiesterases (PDEs) $[10,11]$. cAMP exerts its actions by targeting the downstream effectors such as cAMP-dependent protein kinase (PKA), exchange proteins directly activated by cAMP (EPACs), and cyclic nucleotide-gated ion channels (CNGC). PKA is a major effector that can subsequently phosphorylate cAMP response element binding protein (CREB). CREB is an essential transcriptional co-factor which initiates an array of transcriptional cascades and target gene expressions [12].

Given the crucial roles of cAMP plays, perturbing the cAMP signaling processes may cause cell metabolic disorder and multiple organism diseases. Cancer is one of the tumor development diseases caused by abnormal cell proliferation and differentiation, mainly presents as apoptosis inhibition and insufficient cell death. Current 
progress in cancer field has disclosed a lot of rational methods in dealing with tumor formation [13-16], and many scientists have turned their attention to the universal small organic molecule cAMP, which influences vital cellular signaling transduction and regulates physiological metabolic processes [17-21]. Therefore, cAMP has become an ideal target for contemporary therapies for cancer and tumor diseases, as well as combating bacteria virulence and developing new drugs. Although numerous approaches seek to target the cAMP signaling system, such as synthanses, hydrolyases, and downstream effector proteins and RNAs, the precise molecular mechanism of cAMP causes or defenses against cancer is still relatively unclear and the clinical treatment effect is also less reported. Bibliometrics has been widely used in the analysis of research output, as well as the discovery of hotspots and research trends [22]. So bibliometrics is helpful to understand the knowledge base and research frontier of a specific field. In addition, CiteSpace which is developed by Chaomei Chen is an effective visualization software based on bibliometrics $[23,24]$. However, there is no bibliometric study on cAMP signaling system in the cancer field to date. In this study, the research literatures on the role of cAMP signaling system in the field of cancer published in the past decade were retrieved from the Web of Science and analyzed by the bibliometric study. The purpose of this scientometric study is to analyze the research literatures of cAMP signaling system with its linkage to cancer, and explore the research trends, hotspots and other useful information in this field.

\section{Materials and Methods}

\section{Data source and search strategy}

Relevant literatures were collected in the Web of Science Core Collection (WoSCC) database which was widely used in bibliometric analysis $[25,26]$. The search query was "TS (Topics) $=$ ("cAMP" or "cyclic adenosine monophosphate" or "cyclic AMP" or

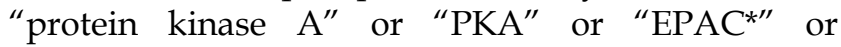
"CNGC") and TS= ("tumor" or "cancer" or "carcino*" or "onco*")" (the symbol "*" is a retrieval symbol of WOS advanced retrieval, which means to search for words prefixed with the word before "*"). Research results were restricted by language (English) and document type (Article). Publication year was restricted from 2009 to 2019. Literature search was completed within a day to avoid bias caused by database updates. A total of 4590 articles were retrieved. Considering that the word "camp" has the meaning of vacation camp, the retrieved literature was screened, and the articles that the definition of "camp" is not cyclic adenosine monophosphate were excluded. 284 articles and duplicate literature were screened out, so a total of 4306 articles were included in this analysis.

\section{Data analysis tools}

EndNote X9 was used to remove duplicate articles, and then irrelevant articles were manually filtered. CiteSpace V was used to complete bibliometric analyses of categories, countries and institutions, co-cited journals, authors and co-cited authors, co-occurrence of keywords and references. The parameters of CiteSpace were set as follows: time slicing (from 2009 to 2019, one year per slice); term source (title, abstract, author keywords, keywords plus); node types (select author, institution, country, keyword, category, reference, cited author and cited journal in turn); strength (cosine); scope (within slices); selection criteria (top 50).

The visualization map is mainly composed of many nodes and interwoven connections. Nodes represent different subject categories. The size of each node indicates the number or citation frequency. The larger the circle, the more literature belongs to this research field. Each circle is made up of different color rings, and each color corresponds to the time scale. The change of color from cold blue tone to warm red tone in the time scale indicates the change of time from early to recent. If the periphery of a node is bright red or bright purple, it represents that the node is a burst node or its betweenness centrality is bigger than 0.10 . Betweenness centrality measures the degree of one node in the middle of a path that connects to other nodes in the network. The nodes with high centrality are located in the center of the network, which are the transitions of other parts. The line which links two circles indicates that they are connected or cooperated or co-cited. The thickness of a line is proportional to its strength or correlation $[27,28]$.

\section{Results and Discussion}

\section{Analysis of the basic situation of the extracted literature}

\section{Analysis of publication outputs}

In this study, 4306 articles were included. The number of annual publications was generally considerable, but the number in the year of 2013 and 2019 was relatively small compared with that of other years (Figure 1A). There was no obvious research trend but kept relatively stable from 2009 to 2019. In order to understand the general research trend of cAMP signaling system with its linkage to cancer in the past decade, the trend line of publications in the 
scatter plot was drawn in Figure 1B. The trend line was stable with a slight upward tendency. Based on these results, it can be inferred that the corresponding research is in a plateau period in recent years. As is known to all, the topic of cancer has always been a hotspot in various fields for a long time, while the related research of cAMP signaling system is also at a mature stage, there may be some new breakthroughs in the next few years.

\section{Analysis of categories}

CiteSpace's co-occurrence analysis of subject categories, which is based on Web of Science category, is an effective way to understand the related research fields. Visual calculation results show that these 4306 papers mainly appear in 105 research fields. Table $\mathbf{1}$ shows the ranking of subject categories according to

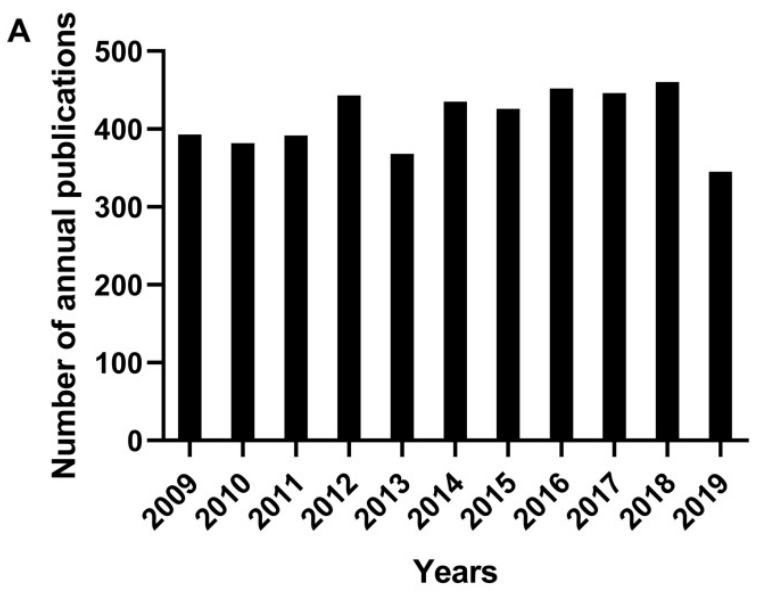

the publication frequency and betweenness centrality, respectively. "Biochemistry \& molecular biology" (997; 0.25$)$ accounted for the largest proportion and had the second highest centrality. In addition, "Pharmacology \& Pharmacy" (481; 0.27), "Cell Biology" (823; 0.11), "Neurosciences \& Neurology" (254; 0.14$)$ and "Chemistry" $(214 ; 0.15)$ also had a high frequency and centrality. Figure 2 shows the co-occurrence network of subject categories. The nodes of "Biochemistry \& Molecular Biology", "Pharmacology \& Pharmacy" and "Cell Biology" are relatively large, and the outer rings of these circles are purple, indicating that most of the researches of cAMP signaling system in the cancer field focus on these three directions. Thus, studies in these research areas are of great significance to other areas.

B

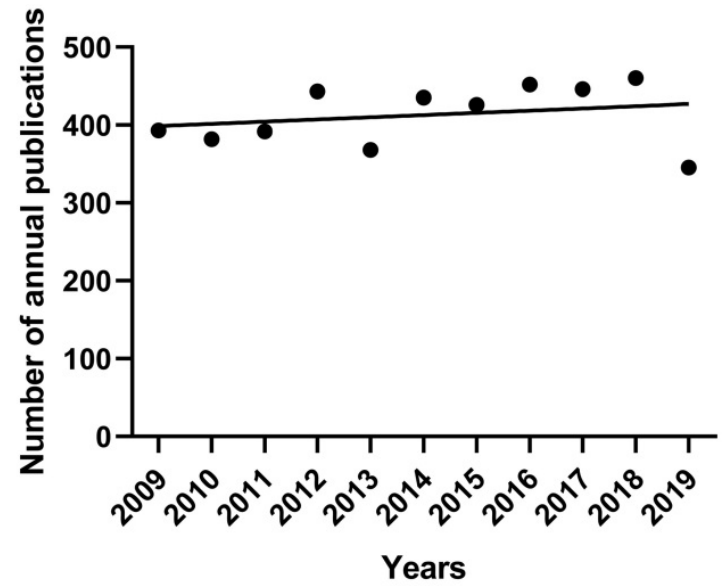

Figure 1. The number of annual publications on the research of cAMP signaling system with its linkage to cancer from 2009 to 2019 . (A) Histogram of the number of annual publications. (B) Scatter plot and trend line of the number of annual publications.

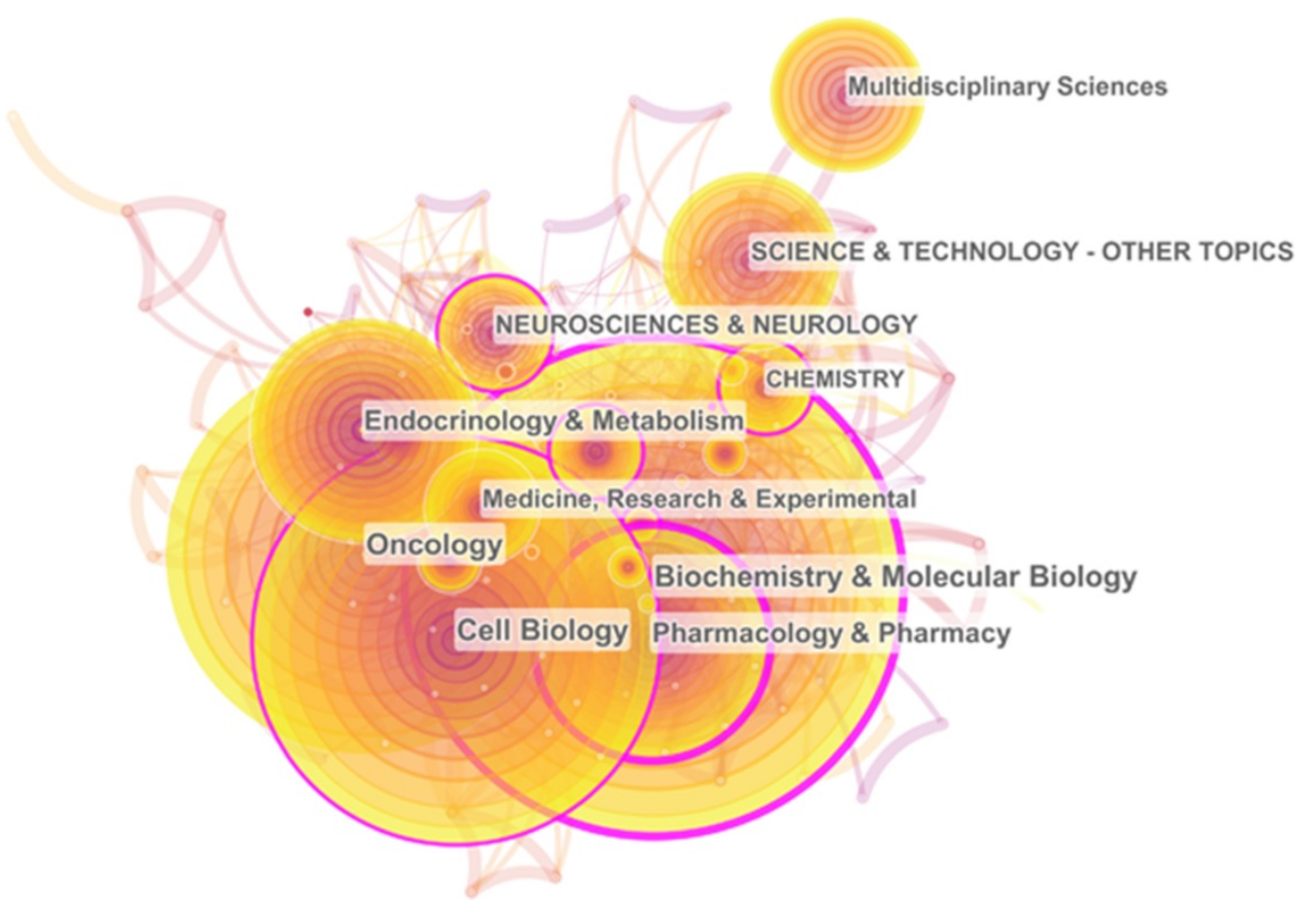

Figure 2. The co-occurrence network of subject categories. 

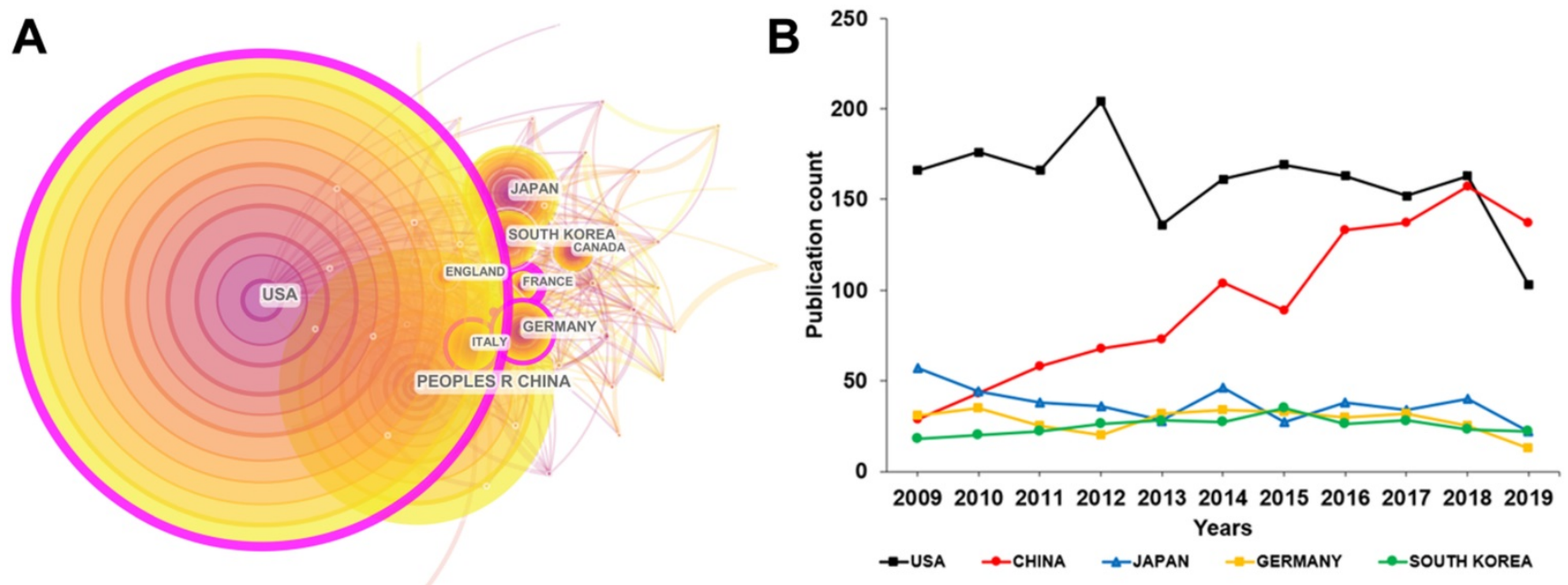

Figure 3. (A) Collaboration network map of leading countries for cAMP signaling system with its linkage to cancer from 2009 to 2019 . (B) Time-varying trend of the number of published publications in the top five countries each year.

Table 1. Top ten categories of cAMP signaling system with its linkage to cancer from 2009 to 2019

\begin{tabular}{llll}
\hline Rank & Category & Count & Category \\
\hline 1 & Biochemistry \& Molecular Biology & 997 & Pharmacology \& Pharmacy \\
2 & Oncology & 826 & Biochemistry \& Molecular Biology \\
3 & Cell Biology & 823 & Immunology \\
4 & Pharmacology \& Pharmacy & 481 & Biotechnology \& Applied Microbiology \\
5 & Endocrinology \& Metabolism & 478 & Chemistry \\
6 & Science \& Technology - Other Topics & 378 & Neurosciences \& Neurology \\
7 & Multidisciplinary Sciences & 359 & Physiology \\
8 & Medicine, Research \& Experimental & 264 & Toxicology \\
9 & Neurosciences \& Neurology & 254 & Cell Biology \\
10 & Chemistry & 214 & Hematology \\
\hline
\end{tabular}

\section{Analysis of leading countries and institutions}

These publications were contributed by 86 countries. Figure 3A with 57 nodes and 389 links shows these authors' countries and their collaboration network. The circles and lines in Figure 3A respectively represent each country's output and their collaboration. United States of America (USA) was the most productive country with 1758 publications. The People's Republic of China (China) ranked second with 1028 publications. Japan (410), Germany (310) and South Korea (275) ranked third to fifth. To sum up, USA, China, Japan, Germany, South Korea, Italy, Canada, France and England played a major role in the research of cAMP signaling system with its linkage to cancer.

Each country had a different publication trend. Figure 3B displays the time-varying trend of the annual publications in the top five countries. Although the largest amount of the publications was contributed by USA, it performed a decreasing trend after 2012, while China showed a continuous upward trend over time. It can be predicted that in the next few years, China will surpass USA in the number of publications and leap to the top. The reasons why a developing country can increasingly publish a huge quantity of research on cAMP with its linkage to cancer are as follows. Firstly, Chinese government's investment in scientific research, especially the basic medical research is increasing. Secondly, as a country with a large population, China has a substantial absolute number of people suffering from cancer and other diseases, which needs more urgent attention and treatment.

There are 3654 institutions involved in these publications. As shown in Table 2, the most productive institution was Chinese Academy of Sciences (65), followed by Shanghai Jiao Tong University (60), University of Texas MD Anderson Cancer Center (56), Seoul National University (54) and University of California- San Diego (49) respectively. Among the top ten institutions according to the number of publications, most were from China and USA, which corresponded to the distribution of the country. Figure S1 shows the collaboration network among these institutions. From the perspective of inter-agency cooperation, there was closer cooperation between institutions within the same country and less collaboration between different countries. The collaboration between USA and other countries was relatively more. National Cancer Institute (0.15), University of Texas MD Anderson 
Cancer Centre (0.13), University of Pennsylvania (0.13), Harvard University (0.12), Chinese Academy of Sciences (0.11) and University of California-Los Angeles (0.11) were the main centers of institutional collaboration worldwide. If there is more cooperation among institutions from different countries, it may be helpful to make new breakthroughs in cAMP signaling system with its linkage to cancer.

Table 2. Top ten institutions contributed to publications on cAMP signaling system with its linkage to cancer from 2009 to 2019

\begin{tabular}{llll}
\hline Rank & Count & Institution & Country \\
\hline 1 & 65 & Chinese Acad Sci & China \\
2 & 60 & Shanghai Jiao Tong Univ & China \\
3 & 56 & Univ Texas MD Anderson Canc Ctr & USA \\
4 & 54 & Seoul Natl Univ & South \\
& & & Korea \\
5 & 49 & Univ Calif San Diego & USA \\
6 & 46 & NCI & USA \\
7 & 45 & Univ Calif Los Angeles & USA \\
8 & 44 & China Med Univ & China \\
9 & 39 & Peking Univ & China \\
10 & 39 & Eunice Kennedy Shriver Natl Inst Child Hlth \& Hum & USA \\
\hline
\end{tabular}

\section{Analysis of cited journals}

Since the influence of a journal mainly depends on its citation times, the citation analysis of journals reflects the distribution of knowledge base and important research findings in a specific field [29]. A total of 76 journals were extracted. Table 3 presents the top ten cited journals based on the citation frequency, including Journal of Biological Chemistry (J Biol Chem, 3112), Proceedings of the National Academy of Sciences of the United States of America (P Natl Acad Sci USA, 2680), Nature (2086), Cancer Research (Cancer Res, 2047), Science (1785), Cell (1688), Oncogene (1511), Plos One (1416), Molecular and Cellular Biology (Mol Cell Biol, 1413) and Biochemical and Biophysical Research Communications (Biochem Bioph Res Co, 1307). From the perspective of citation frequency and centrality, $\mathrm{J}$ Biol Chem (3112; 0.42), Cancer Res $(2047 ; 0.19)$ and P Natl Acad Sci USA $(2680 ; 0.12)$ were at the core of these 76 journals. Among the top ten cited journals, Nature (43.070) had the largest impact factor (IF), followed by Science (41.037) and Cell (36.216) respectively. According to the Journal Citation Reports (JCR) 2019 standard, six journals were classified as Q1. Eight of these journals are published in USA and two in England. USA provides a reliable platform for the publication of relevant research papers. Of the 76 journals, $34.21 \%$ of their IF (2019) were more than ten, while $22.37 \%$ were between five and ten, and the remaining $43.42 \%$ were less than five. This result indicates that a relatively large proportion of cited articles are high-quality researches and published in high-IF journals, implying that cAMP signaling is a very hot, interesting and promising field in cancer topic, which has attracted a lot of attentions of scientists all over the world.

\section{Analysis of author information}

The information of authors and co-cited authors was also analyzed by CiteSpace V. These 4306 articles were produced by 26677 authors. The top ten productive authors and the top ten authors with the largest number of citations were listed in the Table 4 . Stratakis CA was the most productive author who published 46 articles, followed by Bertherat J (21), Nesterova M (11), Horvath A (11), Zhang W (10), Schuller HM (10), Al-Wadei HA (9), Stocco DM (9), Rubin JB (9) and Kawabata T (8) respectively. Most of them come from USA. However, these top ten high-yield authors together accounted for merely $3.34 \%$ of the total literatures, and only six authors had published ten or more articles during the past decade, which indicated that few high-yield researchers had devoted all their energy to the study of cAMP signaling system in cancer field. In addition, some researchers focused on cAMP and cancer studies are due to their cooperation teams, which could be found through the co-authorship network. Although the co-authorship network of this study was very fragmented (Figure 4A), some researchers still established collaborations with each other. Stratakis CA, Bertherat J, Nesterova $\mathrm{M}$ and Horvath A had a close cooperation from 2009 to 2012 (Figure 4B). Kawabata T, Fujita K, Sakai G, MatsushimaNishiwaki R, Otsuka T, Kozawa $\mathrm{O}$ and Tokuda $\mathrm{H}$ worked together in 2018 (Figure 4C). Schuller HM and Al-Wadei HA had a connection from 2012 to 2013 (Figure 4D). In Figure 4C, all the authors come from Nagoya City University Graduate School of Medical Sciences and Gifu University Graduate School of Medicine in Japan. Thus, geographical location may be the main reason for the dispersion of cooperative networks.

However, the analysis of co-author relationship only provides the information about authors' outputs and collaboration situation instead of the authors' impact on the cAMP signaling system with its linkage to cancer, which can be reflected by co-cited author analysis. Two or more authors that are cited together are called co-cited authors. As shown in Table 4, Livak KJ (166) had the largest number of citation, followed by Mayr B (149), Kirschner LS (114), Wang Y (110), Shaywitz AJ (99), Li Y (94), Jemal A (91), Zhang Y (85), Stocco DM (82) and Taylor SS (75) respectively. Of these top ten co-cited authors, nine come from USA and one from China. This result shows that the research findings of USA scholars provide most abundant knowledge for the research of cAMP 
signaling system in cancer field. CiteSpace was also used to draw the author co-citation network map (Figure S2). The centrality of five cited-authors including Taylor SS (0.15), Mayr B (0.14), Livak KJ (0.12) Hanahan D (0.12) and Houslay MD (0.11) was greater than 0.1 , indicating that they played an important connecting role in the network of co-cited authors. The articles written by Mayr B, Livak KJ and Taylor SS are not only highly cited, but also an important connecting point. For example, a review "Transcriptional Regulation by the PhosphorylationDependent Factor CREB" [30] written by Mayr B et al. that published in Nature Reviews Molecular Cell Biology was cited 1,724 times. This review mainly focuses on some summarized mechanisms that have mediated by CREB signal specifically. Livak $\mathrm{KJ}$ et al. [31] introduced the $2^{-\Delta \Delta C_{T}}$ method which may be a convenient and useful method to analyze quantitative real-time polymerase chain reaction data in the article entitled "Analysis of Relative Gene Expression Data Using Real-Time Quantitative PCR and the $2^{-\Delta \Delta C_{T}}$ Method ". This method was used in many researches in this field to calculate relative gene expression [32, 33, 34]. Taylor SS had an in-depth research on PKA and also published numerous high-quality papers in high impact journals [35, 36, 37].

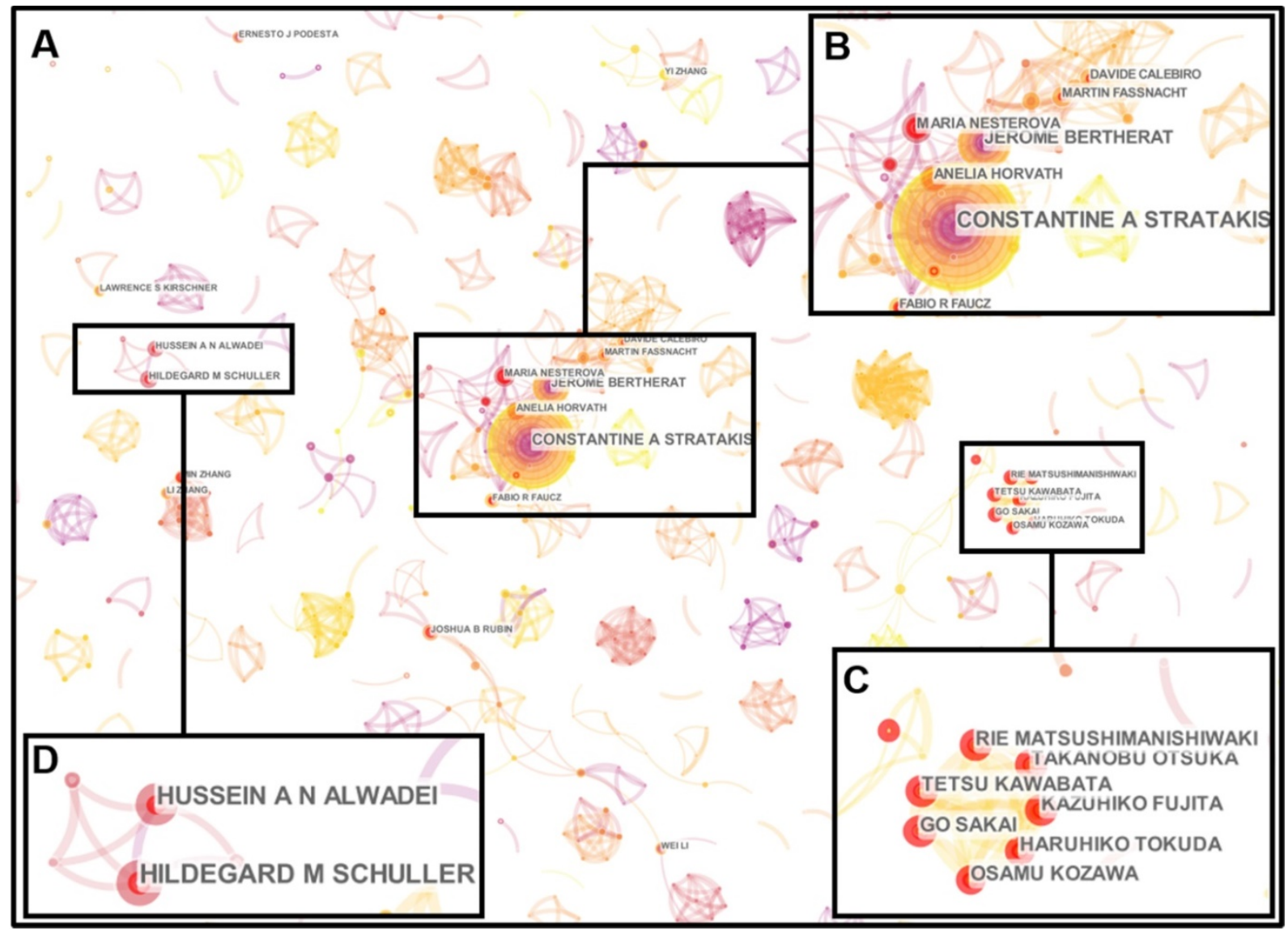

Figure 4. Co-authorship network map. (A) The author collaboration network constructed by CiteSpace was observed with 1036 nodes and 2041 links. Each node represents an author, and each link reflects the collaboration relationship. (B) Stratakis CA, Bertherat J, Nesterova M and Horvath A had a close collaboration from 2009 to 2012. (C) Kawabata T, Fujita K, Sakai G, Matsushima-Nishiwaki R, Otsuka T, Kozawa O and Tokuda H had work together in 2018. (D) Schuller HM and Al-Wadei HA had a connection from 2012 to 2013 .

Table 3. Top ten journals contributed to publications on cAMP signaling system in cancer field from 2009 to 2019

\begin{tabular}{lllll}
\hline Rank & Citation & Cited Journal & IF (2018) & Journal Citation Reports (JCR) \\
\hline 1 & 3112 & Journal of Biological Chemistry & 4.106 & Q2 \\
2 & 2680 & Proceedings of the National Academy of Sciences of the United States of America & 9.580 & Q1 \\
3 & 2086 & Nature & 43.070 & Q1 \\
4 & 2047 & Cancer Research & 8.378 & Q1 \\
5 & 1785 & Science & 41.037 & Q1 \\
6 & 1688 & Cell & 36.216 & Q1 \\
7 & 1511 & Oncogene & 6.634 & Q1 \\
8 & 1416 & Plos One & 2.776 & Q3 \\
9 & 1314 & Molecular and Cellular Biology & 2.705 & Q2 \\
10 & 1307 & Biochemical and Biophysical Research Communications & 3.735 & Q3 \\
\hline
\end{tabular}


Table 4. The top ten active authors and co-cited authors contributed to publications on CAMP signaling system in cancer field from 2009 to 2019

\begin{tabular}{lllllll}
\hline Rank & \multicolumn{2}{l}{ Top 10 productive author } & \multicolumn{4}{l}{ Top 10 co-cited author } \\
\cline { 2 - 6 } & Author & Country & Count & Co-cited author & Country & Citation \\
\hline 1 & Stratakis CA & USA & 46 & Livak KJ & USA & 166 \\
2 & Bertherat J & France & 21 & Mayr B & USA & 149 \\
3 & Nesterova M & France & 11 & Kirschner LS & USA & 114 \\
4 & Horvath A & France & 11 & Wang Y & USA & 110 \\
5 & Zhang W & China & 10 & Shaywitz AJ & USA & 99 \\
6 & Schuller HM & USA & 10 & Li Y & USA & 94 \\
7 & Al-Wadei HA & USA & 9 & Jemal A & USA & 91 \\
8 & Stocco DM & USA & 9 & Zhang Y & China & 85 \\
9 & Rubin JB & USA & 9 & Stocco DM & USA & 82 \\
10 & Kawabata T & Japan & 8 & Taylor SS & USA & 75 \\
\hline
\end{tabular}

Table 5. The top 20 keywords

\begin{tabular}{llll}
\hline Rank & Frequency & Keywords & Centrality \\
\hline 1 & 977 & expression & 0.12 \\
2 & 761 & cAMP & 0.09 \\
3 & 650 & activation & 0.07 \\
4 & 514 & cancer & 0.07 \\
5 & 482 & gene expression & 0.14 \\
6 & 420 & phosphorylation & 0.03 \\
7 & 400 & apoptosis & 0.13 \\
8 & 368 & cell & 0.04 \\
9 & 354 & protein kinase a & 0.12 \\
10 & 334 & proliferation & 0.08 \\
11 & 328 & growth & 0.03 \\
12 & 320 & pathway & 0.04 \\
13 & 299 & in vitro & 0.06 \\
14 & 294 & protein & 0.04 \\
15 & 290 & breast cancer & 0.05 \\
16 & 274 & receptor & 0.02 \\
17 & 252 & inhibition & 0.02 \\
18 & 242 & gene & 0.07 \\
19 & 233 & cancer cell & 0.06 \\
20 & 222 & CREB & 0.08 \\
\hline
\end{tabular}

\section{Analysis of the basic contents of extracted documents}

The frontiers and hotspots of cAMP research in the cancer field can be found by analyzing the results of co-occurrence keywords, co-cited references, burst terms and burst references.

\section{Analyses of keywords and burst terms}

Keywords are highly refined research content and important indicator to reflect the research theme and hotspots. There were 98 keywords extracted from 4306 articles with 98 nodes and 747 links by CiteSpace (Figure S3). The top 20 most frequently occurring keywords can be divided into four categories, 1) molecules regulating cAMP signaling pathway, including 'cAMP' (761), 'phosphorylation' (420), 'protein kinase a' (354), 'pathway' (320), 'protein' (294), 'receptor' (274), 'gene'(242) and 'CREB' (222); 2) the intervention of cAMP pathway, including 'activation' (650) and 'inhibition' (252); 3) experimental subjects, including 'cancer' (514), 'cell'
(368), 'in vitro' (299), 'breast cancer' (290), 'cancer cell' (233); 4) experimental observation results, including the highest frequency word 'expression' (977), 'gene expression' (482), 'apoptosis' (400), 'proliferation' (334) and 'growth' (328) (Table 5). Among them, 'expression' (0.12), 'gene expression' (0.14), 'apoptosis' (0.13) and 'protein kinase a' (0.12) are key nodes, because their betweenness centrality are greater than 0.1 , which means they play an important role in linking other keywords.

Burst term refers to a word or an article that appears to rise suddenly over a period of time, which is an important index to deduce the research frontier in the field of characteristic research [38]. 38 keywords with the strongest citation burst were extracted in this study. Burst strength and duration are two indexes to evaluate burst terms. Figure 5 was a sorted list of burst terms according to their occurrence time. Keyword emergence duration was indicated by red bars. These burst terms can be divided into 5 classes: 1) cAMP signaling pathway including 'binding protein', 'protein kinase $\mathrm{c}^{\prime}$, 'messenger RNA', 'dependent protein kinase', 'signal transduction', 'PKA', 'element binding protein'; 2) other molecules that may be affected by cAMP pathway including 'TNF alpha', 'tumor necrosis factor', 'growth factor receptor', 'growth factor', 'necrosis factor alpha'; 3) experimental object including 'rat', 'epithelial cell', 'target', 'endothelial cell', 'tumor cell', 'breast cancer cell', 'stem cell'; 4) experimental treatment including 'activated protein kinase', 'down regulation' , 'inhibitor', 'induction'; 5) experimental observation results including 'induced apoptosis', 'steroidogenesis', 'angiogenesis', 'migration', 'progression', 'metastasis', 'survival', 'hepatocellular carcinoma', 'lung cancer', 'carcinoma', 'therapy', 'colorectal cancer', 'cell proliferation', 'invasion', 'oxidative stress'. As shown in Figure 5, 9 keywords including 'migration', 'metastasis', 'hepatocellular carcinoma', 'lung cancer', 'carcinoma', 'therapy', 'colorectal cancer', 'invasion' and 'oxidative stress' burst after 2014 and continued to 2019. Among them, 'migration' (10.935), 'metastasis' (16.414), 'lung cancer' (10.691), 'therapy' (16.499), 'colorectal cancer' (10.779) and 'invasion' (12.0687) had relatively stronger citation bursts. The early studies focused on molecules that may be affected by cAMP signaling pathways, such as TNF alpha, tumor necrosis factor and necrosis factor alpha, whereas recent studies are more interested in experimental phenomena such as migration, metastasis, therapy, invasion, lung cancer and so on. 


\begin{tabular}{|c|c|c|c|c|}
\hline Keywords & Year & Strength Begin & End & $2009-2019$ \\
\hline tnf alpha & 2009 & 8.40912009 & 2011 & \\
\hline tumor necrosis factor & 2009 & 10.73952009 & 2011 & \\
\hline binding protein & 2009 & 11.01642009 & 2010 & \\
\hline growth factor receptor & 2009 & 14.17312009 & 2010 & \\
\hline protein kinase $c$ & 2009 & 9.9652009 & 2010 & \\
\hline messenger ma & 2009 & 14.89132009 & 2013 & \\
\hline growth factor & 2009 & 11.68792009 & 2014 & \\
\hline activated protein kinase & 2009 & 4.7422010 & 2011 & \\
\hline induced apoptosis & 2009 & 8.862010 & 2011 & \\
\hline rat & 2009 & 9.90452010 & 2011 & \\
\hline steroidogenesis & 2009 & 7.23772011 & 2013 & \\
\hline necrosis factor alpha & 2009 & 8.63332011 & 2012 & \\
\hline down regulation & 2009 & 8.94452011 & 2013 & \\
\hline dependent protein kinase & 2009 & 8.94452011 & 2013 & \\
\hline epithelial cell & 2009 & 8.30942011 & 2012 & \\
\hline target & 2009 & 4.05762012 & 2013 & \\
\hline signal transduction & 2009 & 5.27612012 & 2014 & \\
\hline endothelial cell & 2009 & 6.52752013 & 2014 & \\
\hline angiogenesis & 2009 & 6.56712013 & 2016 & \\
\hline tumor cell & 2009 & 5.27592013 & 2015 & \\
\hline inhibitor & 2009 & 6.41612013 & 2014 & \\
\hline migration & 2009 & 10.93532014 & 2019 & \\
\hline progression & 2009 & 5.74582014 & 2016 & \\
\hline induction & 2009 & 2.82014 & 2015 & \\
\hline breast cancer cell & 2009 & 4.5262014 & 2015 & \\
\hline stem cell & 2009 & 9.68272014 & 2015 & \\
\hline metastasis & 2009 & 16.41412015 & 2019 & \\
\hline pka & 2009 & 3.00542015 & 2017 & \\
\hline survival & 2009 & 6.90432015 & 2016 & \\
\hline element binding protein & 2009 & 5.55832015 & 2016 & \\
\hline hepatocellular carcinoma & 2009 & 8.78042015 & 2019 & \\
\hline lung cancer & 2009 & 10.69112016 & 2019 & \\
\hline carcinoma & 2009 & 5.37652016 & 2019 & \\
\hline therapy & 2009 & 16.49862016 & 2019 & \\
\hline colorectal cancer & 2009 & 10.77882016 & 2019 & \\
\hline cell proliferation & 2009 & 9.79282016 & 2017 & \\
\hline invasion & 2009 & 12.06872017 & 2019 & \\
\hline oxidative stress & 2009 & 7.83862017 & 2019 & \\
\hline
\end{tabular}

Figure 5. The list of the top 38 keywords with the strongest citation bursts according to their occurrence time. (Note: The red bars mean these keywords cited frequently, while the blue bars mean infrequent citation.)

\section{Analysis of co-cited references}

The literature cited together in a group of publications is called co-cited reference, which is one of the most important indicators of bibliometrics. Based on the spectral clustering algorithm, CiteSpace can be used to construct the co-cited references' citation network map. There were 630 nodes and 1781 links on this citation network map as shown in Figure 6. 128 clusters were calculated, and 16 clusters listed in Table 6 were dominant and contained a large part of these co-cited references. Modularity $Q$ ( $Q$ value) and silhouette ( $\mathrm{S}$ value) are two indicators to evaluate the cluster quality according to the network structure and clustering clarity. $Q$ value is the index to evaluate the quality of the network divided into different independent modules. Generally, $\mathrm{Q}$ value is between zero and one. If $Q$ value is greater than 0.300 , the community structure is significant. $\mathrm{S}$ value is the index to evaluate the homogeneity of distinct members in the same module [28]. When $S$ value equals to 0.700 , clustering is efficient and convincing. If it is above 0.500 , clustering is generally considered reasonable. When $S$ value is infinite, in usual, the number of clustering is one, the selected network may be too small to represent only one research topic. In this cluster analysis (Table 6), Q value is 0.777 and each $S$ value is greater than 0.500 , which means the cluster result is reliable. Each cluster label was selected by index terms from the references based on log-likelihood ratio algorithm. Cluster size represented the number of references contained in each cluster. The top 10 most citation articles and their main findings were listed in Table S1.

Table 6. The basic information of ten clusters

\begin{tabular}{|c|c|c|c|c|}
\hline Cluster ID & Terms & Size & $S$ value & Mean (Year) \\
\hline 0 & naphthol AS-E & 59 & 0.886 & 2008 \\
\hline 1 & exchange protein & 55 & 0.845 & 2012 \\
\hline 2 & proton-sensing GPCR & 43 & 0.847 & 2012 \\
\hline 3 & protein kinase & 43 & 0.858 & 2007 \\
\hline 4 & carney complex & 36 & 0.940 & 2007 \\
\hline 5 & PKA enhancement & 36 & 0.935 & 2007 \\
\hline 6 & inhibitory neurotransmitter & 34 & 0.885 & 2008 \\
\hline 7 & somatic mutation & 34 & 0.904 & 2012 \\
\hline 8 & fibrolamellar carcinoma & 32 & 0.966 & 2014 \\
\hline 9 & pharmacological target & 30 & 0.968 & 2010 \\
\hline 10 & selective indoleamine-2 & 26 & 0.984 & 2013 \\
\hline 11 & MAPK phosphatase-1 & 17 & 0.963 & 2007 \\
\hline 12 & mouse skin papilloma development & 16 & 0.937 & 2005 \\
\hline 13 & dosage-sensitive sex reversal & 16 & 0.991 & 2004 \\
\hline 14 & unfavorable postoperative survival & 12 & 0.994 & 2008 \\
\hline 15 & protein-coupled estrogen receptor & 8 & 0.982 & 2007 \\
\hline
\end{tabular}

Burst nodes usually represent a shift in research. Top ten from the 125 references with the strongest citation bursts were listed in Table S2. Among these 125 articles, Beuschlein F et al. [39], Zhang XM et al. [40] and Horvath A et al. [41] were also listed in the top 10 references with most citations. The timeline view (Figure S4) can reflect the historical evolution trend of different clusters' cited literatures, and thus reflect the change trend of research focus. Literatures related to exchange protein (\#1), proton-sensing GPCR (\#2) and somatic mutation (\#7) were still research hotspots until 2019. The researches related to fibrolamellar carcinoma (\#8) and human indoleamine (\#10) were also the focus nowadays, while the researches on naphthol AS-E (\#0), carney complex $(\# 4)$, ovarian cancer cell migration (\#5) and beta-adrenergic receptor (\#6) only attracted more attention between 2004 and 2011. 


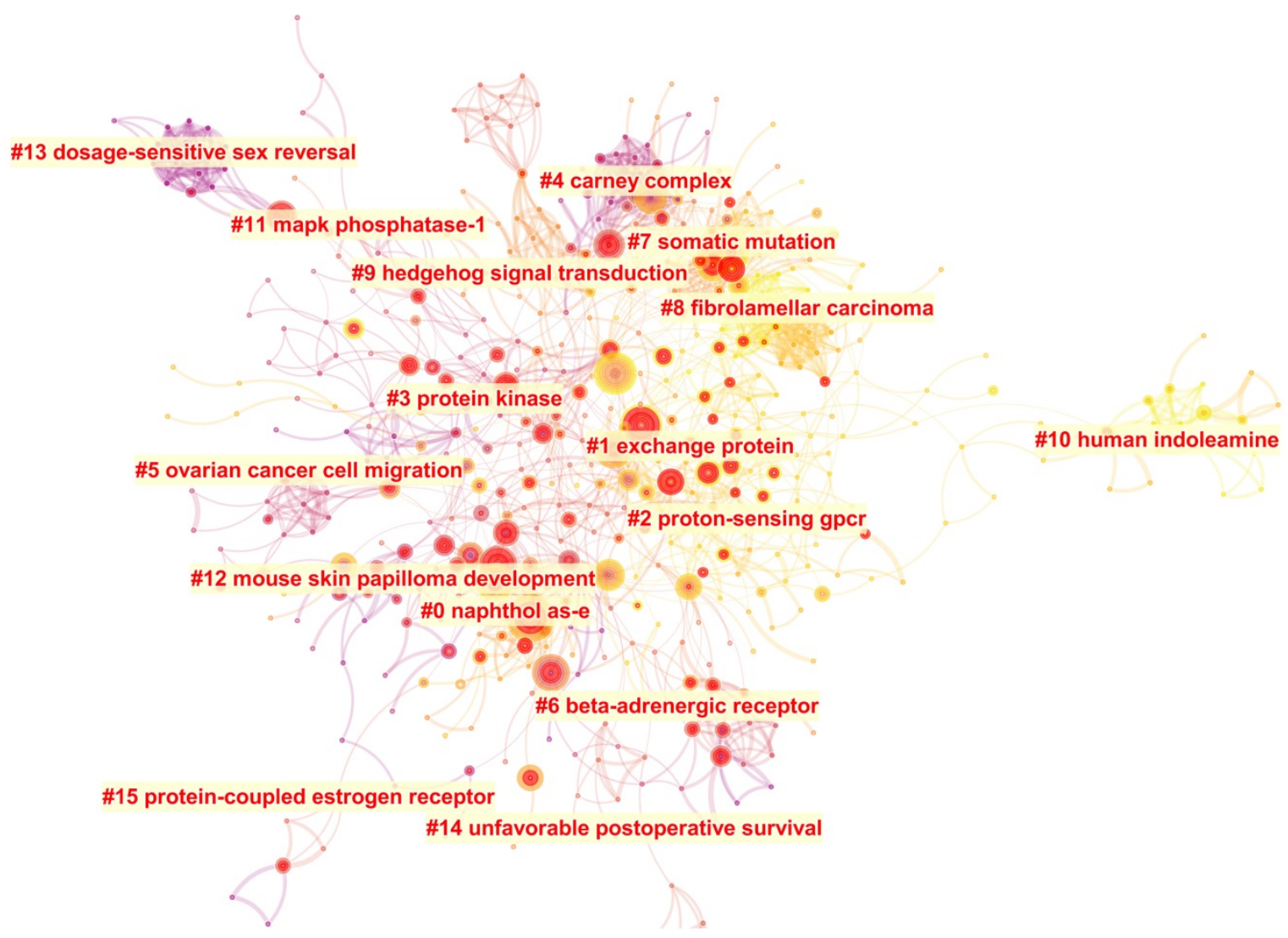

Figure 6. The co-cited references citation network and the 16 corresponding clusters.

\section{Research frontiers and hotspots}

According to the above results, several frontiers and hotspots of research focus on cAMP signaling system in cancer field were extracted as follows:

cAMP signaling pathway is related to cancer cell apoptosis

Generally, cAMP signaling pathway was confirmed to be inhibited in many reported cancer tissues [17]. A lot of studies have shown that if the cAMP level in cancer tissue is enhanced, the apoptosis of tumor cells can be promoted, thus inhibiting tumor growth $[42,43,44]$. Abudoureyimu $\mathrm{A}$ et al. found that $\mathrm{As}_{2} \mathrm{O}_{3}$ induced gastric cancer BGC-823 cell apoptosis by up regulating cAMP level and down regulating PKC level [42]. Daniel PM et al. proposed that the pharmacological activation of cAMP in glioblastoma (GBM) cells led to the increase of proapoptotic BIM (Bcl-2 interacting mediator of cell death) expression and apoptosis in specific types of GBM cells [17]. Cheng YM et al. and Follin-Arbelet V et al. showed that cAMP could induce apoptosis in multiple myeloma cells in vitro $[43,44]$. However, Hara $\mathrm{M}$ et al. showed that vasoactive intestinal peptide could prevent the progression of hepatocellular carcinoma (HCC) by increasing apoptosis through inhibiting cAMP / Bcl-xL pathway [45]. Moreover, Safa M et al. proposed that the increase of cAMP could inhibit the
$\mathrm{As}_{2} \mathrm{O}_{3}$-induced apoptosis in acute promyelocytic leukemia cells [18]. All in all, the effect of cAMP signaling pathway on apoptosis is quite different because of different cell types. Even so, cAMP is still a possible target to inhibit the growth of many tumors.

cAMP signaling pathway is related to cancer cell metastasis

EPAC is one of the major downstream effectors that mediates CAMP signaling [46]. EPAC consists of two subtypes, EPAC1 and EPAC2. Many studies have shown that EPAC1 is related to the metastasis of cancer cells. EPAC1 could promote the metastasis of pancreatic ductal adenocarcinoma (PDA) cells by facilitating the activation and transport of integrin $\beta \mathrm{r}$ $[47,48]$. EPAC1 regulated the metastasis of melanoma cells through syndecan-2 translocation, heparin sulfate (HS) modification and activation of endoplasmic reticulum $\mathrm{Ca}^{2+}$ release via the phospholipase C (PLC)/ inositol triphosphate (IP3) receptor pathway $[49,50,51]$. In triple-negative breast cancer (TNBC) cells, the down-regulation of EPAC1 could reduce the metastasis of TNBC cell lines [52].

However, other studies had shown that overexpression of EPAC1 in bladder cancer cell lines could significantly inhibit cell metastasis without affecting cell viability [53]. The activation of cAMP/ PKA and cAMP/ EPAC1/ RAP1-GTPase pathways could inhibit the metastasis of cervical cancer cells 
[54]. These findings suggested that cAMP signaling pathway had both positive and negative effects on cancer metastasis, which may be related to different cell types of cancer tissues. EPAC1 may be a therapeutic target to inhibit the metastasis of cancer cells.

\section{cAMP signaling pathway is related to Carney complex}

Carney complex (CNC) is a relatively rare autosomal dominant neoplasia syndrome. It was first reported as "the complex of myxomas, spotty pigmentation (lentigines) and endocrine overeactivity" in 1985 [55]. This disease is mainly caused by mutations in PRKAR1A (the gene encoding type $1 \mathrm{~A}$ regulatory subunit of PKA) and interference with the cAMP/PKA signaling pathway. CNC patients predisposed to a variety of tumors. Endocrine tumors are the main cancers associated with $\mathrm{CNC}$, including primary pigmented nodular adrenocortical disease (PPNAD), growth-hormone secreting pituitary adenoma, thyroid and gonadal tumors. Other tumors related to $\mathrm{CNC}$ mainly include myxomas of the heart, psamommatous melanotic schwannomas and so on [56].

Mutations in PDE11A and PDE8B were found in CNC patients with PPNAD $[57,58]$. It was shown that the imbalance of cAMP/ PKA signaling pathway could co-regulate other signaling pathways, which participated in the occurrence of adrenocortical tumors [59]. In addition, the activation of cAMP/PKA signaling pathway may play an important role in hepato-pancreato-biliary tumorigenesis of $\mathrm{CNC}$ patients [60]. These results indicated that cAMP/PKA pathway might be the target for treatment of these lesions [61]. Some researchers had proven that cAMP analogue 8-Cl-adenosine (8-Cl-ADO) could treat CNC-related tumors by inducing apoptosis through intracellular transport and metabolism inhibition [62]. In summary, these studies mainly focus on the mechanism of tumor occurrence and treatment target of CNC patients, and provide ideas for the treatment of CNC-related tumors, in which cAMP signal pathway may be a breakthrough.

\section{Intervening of the CAMP metabolic pathway is a potential way to treat disease or cancer}

Given that the occurrence of many diseases and cancers is related to cAMP pathway, the interference of its possible target may be a promising therapeutic strategy for these diseases or cancers. For example, cAMP agonists can inhibit the growth of GBM cells [17]. The combination of tricyclic antidepressants and the inhibitor of purinergic receptor P2Y12 can delay the occurrence of GBM by increasing cAMP level [63]. The inhibitor of EPAC1 can slow down the remodeling of the heart and may be used as a treatment for cardiovascular diseases such as arrhythmia and heart failure [64]. In addition, a study showed that EPAC1 could promote the metastasis of PDA cells and suggested that EPAC inhibitors might be a potential target of anti-metastasis drugs in PDA [41]. More studies have shown that PDE inhibitors are potential drugs for the treatment of many cancers and other diseases [65-69].

PDE4 inhibitors have been proved to have many functions as follows: 1) reverse the memory impairment caused by $\beta$-amyloid peptide through weakening the inflammation and apoptosis of neurons; improve memory loss and cognitive function in patients with Alzheimer's disease [70,71]; 2) inhibit rheumatoid arthritis by reducing the tumor necrosis factor a (TNF-a) produced by human synovial cells [72];3) treat airway inflammation, such as asthma and chronic obstructive pulmonary diseases through inhibiting the release of TNF- $\alpha$ by human peripheral blood mononuclear cells, the proliferation of lymphocytes and the production of cytokines [73]; 4) treat metabolic diseases related to aging $[74,75] ; 5)$ treat alcoholic fatty liver disease and nonalcoholic fatty liver disease [75-77] and so on. In addition, zardaverine, a double selective PDE3/4 inhibitor, can induce cell cycle arrest in G0/G1 phase of HCC cells by regulating cyclin [78]. In addition, some studies demonstrate that CREB is an important regulatory factor in tumorigenesis and development which is suggested to be a novel target for cancer therapy [79]. As an inhibitor of CREB-mediated gene transcription [80], naphthol AS-E could be used to inhibit breast cancer bone metastasis, acute leukemia cell viability, and so on [81-84]. According to the publications analyzed in this study, tumors and cancers associated with cAMP signaling system in various human body systems are summarized and drawn in Figure 7. Therefore, the treatment targeting cAMP signaling system may be a potential universal approach for fighting against various cancers and other diseases.

\section{Strengths and limitations}

As far as we know, this study is the first bibliometric analysis of the researches related to cAMP signaling system in cancer field. Compared with the traditional literature review, the bibliometric analysis by CiteSpace is more comprehensive and intuitive. However, this study still has some limitations. 1) This study only extracts the literature from the Web of Science Core Collection database. 2) We only selected articles published in English. 3) CiteSapce for bibliometric analysis is only based on the main information on the literature, not the full text. 4) The clustering is although reasonable in terms of $Q$ value and $S$ value, there are still some biases. 


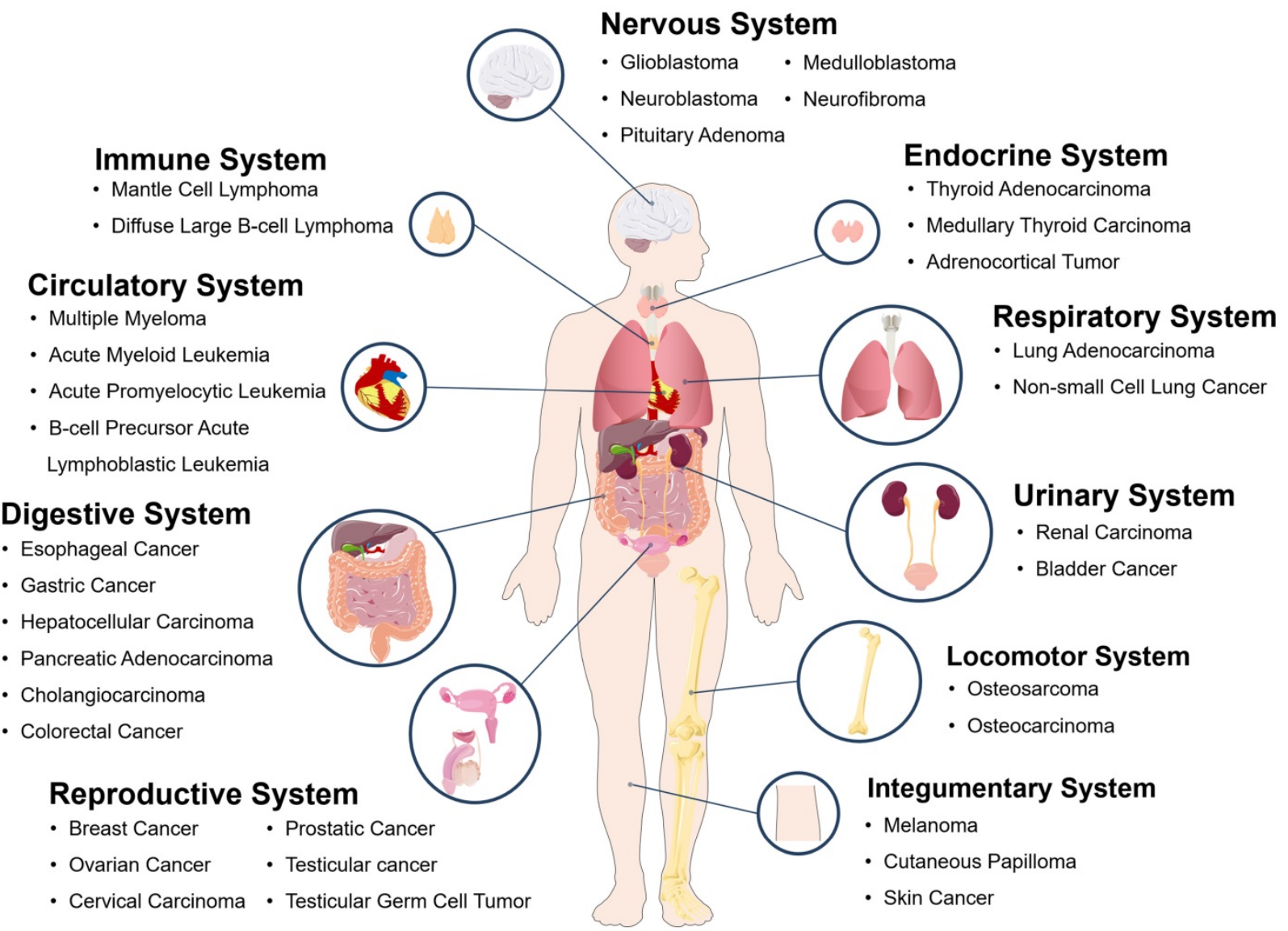

Figure 7. Some tumors and cancers related to CAMP signaling pathway system in various human body systems.

\section{Conclusion}

In summary, this study helps us to understand the basic current research situation of cAMP signaling system in cancer field from 2009 to 2019 . The number of related literatures published each year is relatively stable. In the past decade, USA contributed the most to the research on cAMP signaling system in cancer field, followed by China and Japan. The top three most productive journals were J Biol Chem, P Natl Acad $\mathrm{Sci}$ and Nature. Cooperation between the institutions from different countries needs to be strengthened. Lots of corresponding researches in this field are focused on the apoptosis, metastasis of cancer cell and Carney complex, suggesting that cAMP may become an ideal target for contemporary therapies for cancer and tumor diseases.

\section{Abbreviations}

cAMP: cyclic adenosine monophosphate; ACs: adenylyl cyclases; PDEs: phosphodiesterases; PKA: cAMP-dependent protein kinase; EPACs: exchange proteins directly activated by cAMP; CNGC: cyclic nucleotide-gated ion channels; CREB: cAMP response element binding protein; GBM: glioblastoma; BIM: Bcl-2 interacting mediator of cell death; HCC: hepatocellular carcinoma; PDA: pancreatic ductal adenocarcinoma; HS: heparin sulfate; PLC: phospholipase C; IP3: inositol triphosphate; TNBC: triple-negative breast cancer; CNC: carney complex; PPNAD: primary pigmented nodular adrenocortical disease; 8-Cl-ADO: 8-Cl-adenosine; TNF-a: tumor necrosis factor $\mathrm{a}$.

\section{Supplementary Material}

Supplementary figures and tables.

http://www.jcancer.org/v12p0358s1.pdf

\section{Acknowledgments}

This work was financially supported by the National Natural Science Foundation of China (31800027), the Natural Science Foundation of Hubei Province (2018CFB131), and the Independent Research Project of Wuhan University School of Health Science (ZZKY006).

\section{Author contributions}

All authors read and approved the manuscript. J.S. and C.W. conceived the study and participated in its design, co-ordination and editing. C.T. was responsible for formal analysis, visualization and writing the manuscript. D.L., Y.F., J.Y. and C.L. were 
responsible for the literature screening and participated in the operation of software.

\section{Competing Interests}

The authors have declared that no competing interest exists.

\section{References}

1. Rall TW, Sutherland EW, Wosilait WD. The relationship of epinephrine and glucagon to liver phosphorylase. III. Reactivation of liver phosphorylase in slices and in extracts. J Biol Chem. 1956;218(1):483-495.

2. Lefkimmiatis $\mathrm{K}$, Zaccolo M. cAMP signaling in subcellular compartments. Pharmacol Ther. 2014;143(3):295-304.

3. Kim SN, Ahn YH, Kim SG, et al. 8-Cl-cAMP induces cell cycle-specific apoptosis in human cancer cells[J]. International journal of cancer Journal international du cancer, 2001; 93(1):33-41.

4. Sirotkin AV, Ben OA, Tandlmajerová A, et al. cAMP response element-binding protein 1 controls porcine ovarian cell proliferation, apoptosis, and FSH and insulin-like growth factor 1 response. Reprod Fertil Dev. 2018;30(8):1145-1153.

5. Ricciarelli R, Fedele E. cAMP, cGMP and Amyloid $\beta$ : Three Ideal Partners for Memory Formation. Trends Neurosci. 2018;41(5):255-266.

6. Fernandes HB, Riordan S, Nomura T, et al. Epac2 Mediates cAMP-Dependent Potentiation of Neurotransmission in the Hippocampus. J Neurosci. 2015;35(16):6544-6553

7. Numata T, Sato-Numata K, Okada Y, Inoue R. Cellular mechanism for herbal medicine Junchoto to facilitate intestinal $\mathrm{Cl}$-/water secretion that involves cAMP-dependent activation of CFTR. J Nat Med. 2018;72(3):694-705.

8. Astakhova LA, Kapitskiǐ SV, Govardovskiǔ VI, Firsov ML. cAMP as a Regulator of the Phototransduction Cascade. Ross Fiziol Zh Im I M Sechenova. 2012;98(11):1273-1285.

9. Arumugham VB, Baldari CT. cAMP: a multifaceted modulator of immune synapse assembly and T cell activation. J Leukoc Biol. 2017;101(6):1301-1316.

10. Gerlo S, Kooijman R, Beck IM, Kolmus K, Spooren A, Haegeman G. Cyclic AMP: a selective modulator of NF-kB action. Cell Mol Life Sci. 2011;68(23):3823-3841.

11. Fajardo AM, Piazza GA, Tinsley HN. The role of cyclic nucleotide signaling pathways in cancer: targets for prevention and treatment. Cancers (Basel). 2014;6(1):436-458.

12. Corn PG, El-Deiry WS. Derangement of growth and differentiation control in oncogenesis[J]. Bioessays, 2002, 24(1):83-90.

13. Elbrashy AA, Kamal A, Fahim MI. Methods of Treatment and Outcome for Ovarian Germ Cell Tumors. Indian J Surg Oncol. 2019;10(4):640-642.

14. Triscott J, Rose Pambid M, Dunn SE. Concise review: bullseye: targeting cancer stem cells to improve the treatment of gliomas by repurposing disulfiram. Stem Cells. 2015;33(4):1042-1046

15. Yang CQ, Liu J, Zhao SQ, et al. Recent treatment progress of triple negative breast cancer. Prog Biophys Mol Biol. 2020;151:40-53.

16. Mun EJ, Babiker HM, Weinberg U, Kirson ED, Von Hoff DD. Tumor-Treating Fields: A Fourth Modality in Cancer Treatment. Clin Cancer Res. 2018;24(2):266-275.

17. Daniel PM, Filiz G, Mantamadiotis T. Sensitivity of GBM cells to cAMP agonist-mediated apoptosis correlates with CD44 expression and agonist resistance with MAPK signaling. Cell Death Dis. 2016;7(12): e2494.

18. Safa M, Mousavizadeh $\mathrm{K}$, Noori S, et al. cAMP protects acute promyelocytic leukemia cells from arsenic trioxide-induced caspase-3 activation and apoptosis[J]. European Journal of Pharmacology, 2014, 736:115-123.

19. Cho EA, Juhnn YS. The cAMP signaling system inhibits the repair of $\gamma$-ray-induced DNA damage by promoting Epac1-mediated proteasomal degradation of XRCC1 protein in human lung cancer cells. Biochem Biophys Res Commun. 2012;422(2):256-262.

20. Dicitore A, Grassi ES, Caraglia M, et al. The cAMP analogs have potent anti-proliferative effects on medullary thyroid cancer cell lines. Endocrine. 2016;51(1):101-112.

21. Grassi ES, Dicitore A, Negri I, Borghi MO, Vitale G, Persani L. 8-Cl-cAMP and PKA I-selective cAMP analogs effectively inhibit undifferentiated thyroid cancer cell growth. Endocrine. 2017;56(2):388-398.

22. Guler AT, Waaijer CJF, Palmblad M. Scientific workflows for bibliometrics[J]. Scientometrics, 2016, 107(2):385-398.

23. Wang X, Guo J, Gu D, Yang Y, Yang X, Zhu K. Tracking knowledge evolution, hotspots and future directions of emerging technologies in cancers research: a bibliometrics review. J Cancer. 2019;10(12):2643-2653.

24. Kim MC, Chen C. A scientometric review of emerging trends and new developments in recommendation systems[J]. Scientometrics, 2015, 104(1):239-263.

25. Gao Y, Shi S, Ma W, et al. Bibliometric analysis of global research on PD-1 and PD-L1 in the field of cancer. Int Immunopharmacol. 2019;72:374-384.

26. Li B, Chen Z, Li Y, Yang W, Wang W. Visualization analysis of graphene and its composites for heavy metal wastewater applications. Environ Sci Pollut Res Int. 2019;26(27):27752-27760.
27. Chen C. Searching for intellectual turning points: progressive knowledge domain visualization. Proc Natl Acad Sci USA. 2004; 101 (Suppl 1):5303-5310.

28. Chen C, Ibekwe-Sanjuan F, Hou J. The structure and dynamics of cocitation clusters: A multiple-perspective cocitation analysis[J]. Journal of the American Society for Information Science and Technology, 2010; 61(7):1386-1409.

29. Ye L, Zhang X. Visualizing the knowledge structure of medication-adherence research: A bibliometric analysis (1997-2016). Int J Health Plann Manage. 2019;34(4):1333-1353

30. Mayr B, Montminy M. Transcriptional regulation by the phosphorylation-dependent factor CREB. Nat Rev Mol Cell Biol. 2001;2(8):599-609.

31. Livak KJ, Schmittgen TD. Analysis of relative gene expression data using real-time quantitative PCR and the 2(-Delta Delta C(T)) Method. Methods. 2001;25(4):402-408

32. Yang C, Li X, Wang Y, Zhao L, Chen W. Long non-coding RNA UCA1 regulated cell cycle distribution via CREB through PI3-K dependent pathway in bladder carcinoma cells. Gene. 2012;496(1):8-16.

33. Zhang D, Ma QY, Hu HT, Zhang M. $\beta 2$-adrenergic antagonists suppress pancreatic cancer cell invasion by inhibiting CREB, NFKB and AP-1. Cancer Biol Ther. 2010;10(1):19-29.

34. Pigazzi M, Manara E, Baron E, Basso G. miR-34b targets cyclic AMP-responsive element binding protein in acute myeloid leukemia. Cancer Res. 2009;69(6):2471-2478.

35. Madhusudan, Akamine P, Xuong NH, Taylor SS. Crystal structure of a transition state mimic of the catalytic subunit of cAMP-dependent protein kinase. Nat Struct Biol. 2002;9(4):273-277.

36. Sastri M, Barraclough DM, Carmichael PT, Taylor SS. A-kinase-interacting protein localizes protein kinase A in the nucleus. Proc Natl Acad Sci U S A. 2005;102(2):349-354.

37. Kim C, Xuong NH, Taylor SS. Crystal structure of a complex between the catalytic and regulatory (RIalpha) subunits of PKA. Science. 2005;307(5710):690-696

38. Chen C. CiteSpace II: Detecting and visualizing emerging trends and transient patterns in scientific literature[J]. Journal of the American Society for Information Science and Technology, 2006; 57(3):359-377.

39. Beuschlein F, Fassnacht M, Assié G, et al. Constitutive activation of PKA catalytic subunit in adrenal Cushing's syndrome. $N$ Engl J Med. 2014;370(11):1019-1028

40. Zhang X, Odom DT, Koo SH, et al. Genome-wide analysis of cAMP-response element binding protein occupancy, phosphorylation, and target gene activation in human tissues. Proc Natl Acad Sci U S A. 2005;102(12):4459-4464.

41. Horvath A, Boikos S, Giatzakis C, et al. A genome-wide scan identifies mutations in the gene encoding phosphodiesterase 11A4 (PDE11A) in individuals with adrenocortical hyperplasia. Nat Genet. 2006;38(7):794-800.

42. Abudoureyimu A, Muhemaitibake A. Arsenic trioxide regulates gastric cancer cell apoptosis by mediating cAMP. [J]. European Review for Medical \& Pharmacological Sciences, 2017; 21(3):612.

43. Cheng YM, Zhu Q, Yao YY, Tang Y, Wang MM, Zou LF, 8-Chloroadenosine $3^{\prime}, 5^{\prime}$-monophosphate induces cell cycle arrest and apoptosis in multiple myeloma cells through multiple mechanisms. Oncol Lett. 2012;4(6):1384-1388.

44. Follin-Arbelet V, Hofgaard PO, Hauglin $\mathrm{H}$, et al. Cyclic AMP induces apoptosis in multiple myeloma cells and inhibits tumor development in a mouse myeloma model. BMC Cancer. 2011; 11:301.

45. Hara M, Takeba $\mathrm{Y}$, Iiri $\mathrm{T}$, et al. Vasoactive intestinal peptide increases apoptosis of hepatocellular carcinoma by inhibiting the cAMP/Bcl-xL pathway. Cancer Sci. 2019;110(1):235-244.

46. Rooij JD, Zwartkruis FJT, Verheijen MHG, et al. Epac is a Rap1 guanine-nucleotide-exchange factor directly activated by cyclic AMP[J]. Nature, 1999; 396(6710):474-477.

47. Almahariq M, Chao C, Mei FC, et al. Pharmacological inhibition and genetic knockdown of exchange protein directly activated by cAMP 1 reduce pancreatic cancer metastasis in vivo. Mol Pharmacol. 2015;87(2):142-149.

48. Almahariq M, Tsalkova T, Mei FC, et al. A novel EPAC-specific inhibitor suppresses pancreatic cancer cell migration and invasion. Mol Pharmacol. 2013;83(1):122-128.

49. Baljinnyam E, Iwatsubo K, Kurotani R, et al. Epac increases melanoma cell migration by a heparan sulfate-related mechanism. Am J Physiol Cell Physiol. 2009;297(4):C802-C813.

50. Baljinnyam E, De Lorenzo MS, Xie LH, et al. Exchange Protein Directly Activated by Cyclic AMP Increases Melanoma Cell Migration by a Ca2+-Dependent Mechanism[J]. Cancer Research, 2010; 70(13):5607-5617.

51. Baljinnyam E, Umemura M, De Lorenzo MS, et al. Epac1 promotes melanoma metastasis via modification of heparan sulfate. Pigment Cell Melanoma Res. 2011;24(4):680-687.

52. Kumar N, Prasad P, Jash E, et al. cAMP regulated EPAC1 supports microvascular density, angiogenic and metastatic properties in a model of triple negative breast cancer. Carcinogenesis. 2018;39(10):1245-1253.

53. Ichikawa $\mathrm{H}$, Itsumi $\mathrm{M}$, Kajioka $\mathrm{S}$, et al. Overexpression of exchange protein directly activated by cAMP-1 (EPAC1) attenuates bladder cancer cell migration[J]. Biochem Biophys Res Commun. 2018; 495(1):64-70.

54. Lee JW, Lee J, Moon EY. HeLa Human Cervical Cancer Cell Migration Is Inhibited by Treatment with Dibutyryl-cAMP[J]. Anticancer research, 2014; 34(7):3447-3455 
55. Rothenbuhler A, Stratakis CA. Clinical and molecular genetics of Carney complex[J]. Best Practice \& Research Clinical Endocrinology \& Metabolism, 2010; 24(3):0-399.

56. Stratakis CA. Carney complex: A familial lentiginosis predisposing to a variety of tumors. Rev Endocr Metab Disord. 2016;17(3):367-371.

57. Almeida MQ, Stratakis CA. Carney complex and other conditions associated with micronodular adrenal hyperplasias. Best Pract Res Clin Endocrinol Metab. 2010;24(6):907-914

58. Libé R, Horvath A, Vezzosi D, et al. Frequent phosphodiesterase 11A gene (PDE11A) defects in patients with Carney complex (CNC) caused by PRKAR1A mutations: PDE11A may contribute to adrenal and testicular tumors in CNC as a modifier of the phenotype. J Clin Endocrinol Metab. 2011;96(1): E208-E214.

59. Boikos SA, Horvath A, Heyerdahl S, et al. Phosphodiesterase 11A expression in the adrenal cortex, primary pigmented nodular adrenocortical disease, and other corticotropin-independent lesions. Horm Metab Res. 2008;40(5):347-353.

60. Gaujoux S, Chanson P, Bertherat J, Sauvanet A, Ruszniewski P. Hepato-pancreato-biliary lesions are present in both Carney complex and McCune Albright syndrome: comments on P. Salpea and C. Stratakis. Mol Cell Endocrinol. 2014;382(1):344-345.

61. Saloustros E, Salpea P, Starost M, et al. Prkarla gene knockout in the pancreas leads to neuroendocrine tumorigenesis. Endocr Relat Cancer. 2017;24(1):31-40.

62. Robinson-White AJ, Bossis I, Hsiao HP, Nesterova M, Leitner WW, Stratakis CA. 8-Cl-adenosine inhibits proliferation and causes apoptosis in B-lymphocytes via protein kinase A-dependent and independent effects: implications for treatment of Carney complex-associated tumors. J Clin Endocrinol Metab. 2009;94(10):4061-4069.

63. Shchors K, Massaras A, Hanahan D. Dual Targeting of the Autophagic Regulatory Circuitry in Gliomas with Repurposed Drugs Elicits Cell-Lethal Autophagy and Therapeutic Benefit. Cancer Cell. 2015;28(4):456-471.

64. Lezoualc'h F, Fazal L, Laudette M, Conte C. Cyclic AMP Sensor EPAC Proteins and Their Role in Cardiovascular Function and Disease. Circ Res. 2016;118(5):881-897.

65. Blokland A, Heckman P, Vanmierlo T, Schreiber R, Paes D, Prickaerts J. Phosphodiesterase Type 4 Inhibition in CNS Diseases. Trends Pharmacol Sci. 2019;40(12):971-985.

66. Catalano S, Panza S, Augimeri G, et al. Phosphodiesterase 5 (PDE5) Is Highly Expressed in Cancer-Associated Fibroblasts and Enhances Breast Tumor Progression. Cancers (Basel). 2019;11(11):1740.

67. Sengupta R, Sun T, Warrington NM, Rubin JB. Treating brain tumors with PDE4 inhibitors. Trends Pharmacol Sci. 2011;32(6):337-344.

68. Lin S, Wang J, Wang L, et al. Phosphodiesterase-5 inhibition suppresses colonic inflammation-induced tumorigenesis via blocking the recruitment of MDSC. Am J Cancer Res. 2017;7(1):41-52.

69. Kwak HJ, Nam JY, Song JS, No Z, Yang SD, Cheon HG. Discovery of a novel orally active PDE-4 inhibitor effective in an ovalbumin-induced asthma murine model. Eur J Pharmacol. 2012;685(1-3):141-148.

70. Gulisano W, Tropea MR, Arancio O, Palmeri A, Puzzo D. Sub-efficacious doses of phosphodiesterase 4 and 5 inhibitors improve memory in a mouse model of Alzheimer's disease. Neuropharmacology. 2018; 138:151-159.

71. Wang C, Yang XM, Zhuo YY, et al. The phosphodiesterase-4 inhibitor rolipram reverses $A \beta$-induced cognitive impairment and neuroinflammatory and apoptotic responses in rats. Int J Neuropsychopharmacol. 2012;15(6):749766.

72. McCann FE, Palfreeman AC, Andrews M, et al. Apremilast, a novel PDE4 inhibitor, inhibits spontaneous production of tumour necrosis factor-alpha from human rheumatoid synovial cells and ameliorates experimental arthritis. Arthritis Res Ther. 2010;12(3): R107.

73. Dastidar SG, Ray A, Shirumalla R, et al. Pharmacology of a novel, orally active PDE4 inhibitor. Pharmacology. 2009;83(5):275-286.

74. Wang Z, Liang Y, Zhang L, Zhang N, Liu Q, Wang Z. Phosphodiesterase 4 inhibitor activates AMPK-SIRT6 pathway to prevent aging-related adipose deposition induced by metabolic disorder. Aging (Albany NY). 2018;10(9):2394-2406

75. Park SJ, Ahmad F, Philp A, et al. Resveratrol ameliorates aging-related metabolic phenotypes by inhibiting cAMP phosphodiesterases. Cell. 2012;148(3):421-433

76. Zhang Y, Chen ML, Zhou Y, et al. Resveratrol improves hepatic steatosis by inducing autophagy through the cAMP signaling pathway. Mol Nutr Food Res. 2015;59(8):1443-1457.

77. Rodriguez WE, Wahlang B, Wang Y, et al. Phosphodiesterase 4 Inhibition as a Therapeutic Target for Alcoholic Liver Disease: From Bedside to Bench Hepatology. 2019;70(6):1958-1971.

78. Sun L, Quan H, Xie C, Wang L, Hu Y, Lou L. Phosphodiesterase 3/4 inhibitor zardaverine exhibits potent and selective antitumor activity against hepatocellular carcinoma both in vitro and in vivo independently of phosphodiesterase inhibition. PLoS One. 2014;9(3): e90627.

79. Xiao X, Li BX, Mitton B, Ikeda A, Sakamoto KM. Targeting CREB for cancer therapy: friend or foe. Curr Cancer Drug Targets. 2010;10(4):384-391.

80. Jiang M, Li BX, Xie F, Delaney F, Xiao X. Design, synthesis, and biological evaluation of conformationally constrained analogues of naphthol AS-E as inhibitors of CREB-mediated gene transcription. J Med Chem. 2012;55(8):4020-4024.
81. Jiang M, Yan $\mathrm{Y}$, Yang $\mathrm{K}$, et al. Small molecule nAS-E targeting cAMP response element binding protein (CREB) and CREB-binding protein interaction inhibits breast cancer bone metastasis. J Cell Mol Med. 2019;23(2):1224-1234.

82. Chae HD, Cox N, Capolicchio S, et al. SAR optimization studies on modified salicylamides as a potential treatment for acute myeloid leukemia through inhibition of the CREB pathway. Bioorg Med Chem Lett. 2019;29(16):2307-2315

83. Li BX, Yamanaka K, Xiao X. Structure-activity relationship studies of naphthol AS-E and its derivatives as anticancer agents by inhibiting CREB-mediated gene transcription. Bioorg Med Chem. 2012;20(23):6811-6820.

84. Xie F, Li BX, Kassenbrock A, et al. Identification of a Potent Inhibitor of CREB-Mediated Gene Transcription with Efficacious in vivo Anticancer Activity. J Med Chem. 2015;58(12):5075-5087. 